\title{
Successful treatment of a proximal esophageal rupture with a luminal sponge
}
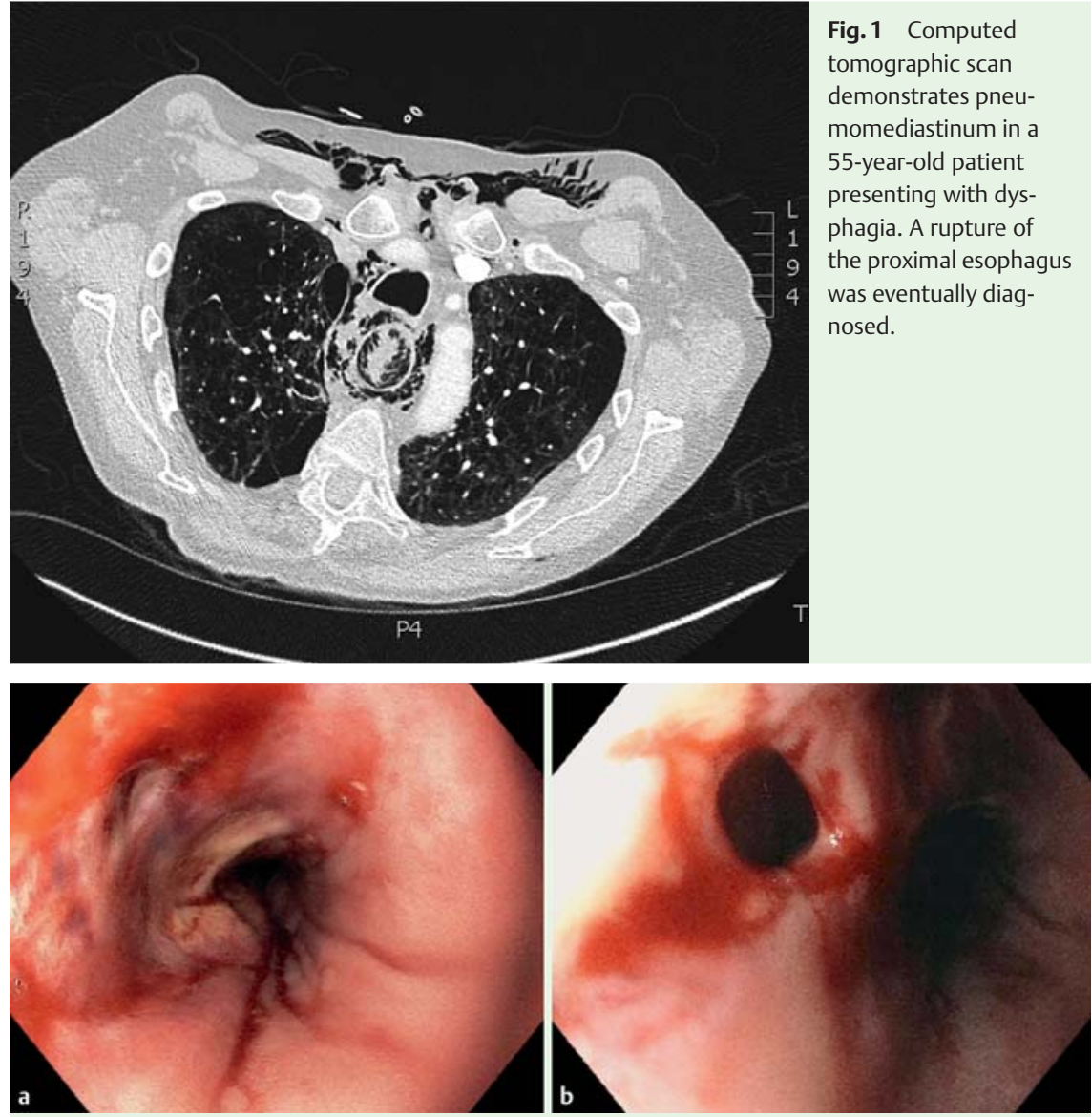

Fig. 3 Placement of the luminal sponge. a Perforation of the esophageal wall. $\mathbf{b}$ Perforation of the esophageal wall from a different angle.
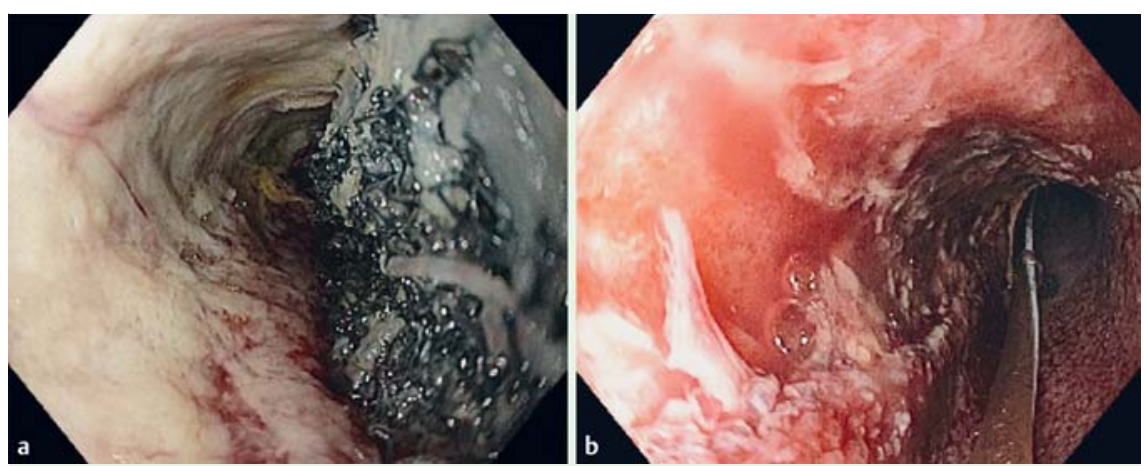

Fig. 4 Removal of the luminal sponge. a Luminal sponge in situ. b Rupture site after removal of the luminal sponge.

A 55-year-old man presented to the emergency department because of dysphagia. On admission, the patient reported retrosternal chest pain, and he was observed to be tachycardic and hypotensive. Physical examination showed soft-tissue emphysema over the sternal notch extending up

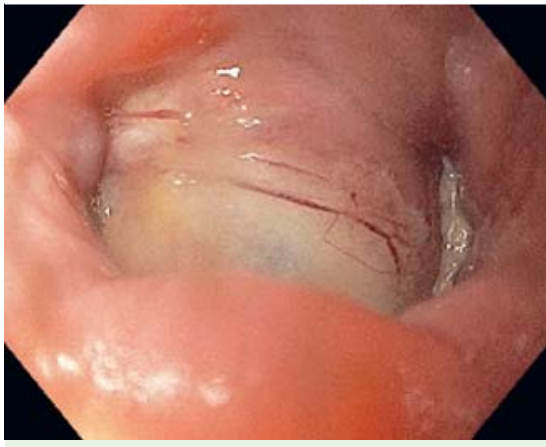

Fig. 2 Initial gastroscopy shows rupture of the upper esophageal sphincter at $15 \mathrm{~cm}$.

ral hematoma at a distance of $19 \mathrm{~cm}$ from the incisors ( $\bullet$ Fig.2). A second gastroscopy after the patient's admission to the intensive care unit 2 hours later revealed mucosal dehiscence at a distance of $18 \mathrm{~cm}$ from the incisors; however, because definite signs of a true transmural perforation were lacking, conservative therapy was initiated.

Follow-up computed tomography revealed the focal pooling of contrast agent at the left side of the proximal esophagus with small, perifocal gas inclusions; therefore, endoscopy was performed again. Besides a large mucosal defect, a 3-mm transmural defect was diagnosed, and a luminal sponge (Endo-SPONGE; B. Braun Medical, Melsungen, Germany) was placed below the UES ( $\bullet$ Fig. 3), as follows:

A 1-0 nonabsorbable suture was fixed at the proximal end of the suction tube within the sponge. When this loop was grasped by a forceps through the working channel, it was possible to position the sponge and the endoscope side by side into the desired location. The use of an overtube was not necessary. The sponge was then kept in place by applying a gentle traction on the tube, which was fixed at the nostril. After 4 days, the sponge was removed by again applying traction on the tube and pulling at the suture loop with the endoscopic forceps. The site of the perforation was covered with fibrin. No mucosal defect was visible ( Fig.4). Gastroscopy after another 7 days showed a sealed lesion without signs of perforation ( $\bullet$ Fig.5). At 2 months after the event, no clinical signs or symptoms of a perforation were detectable. 


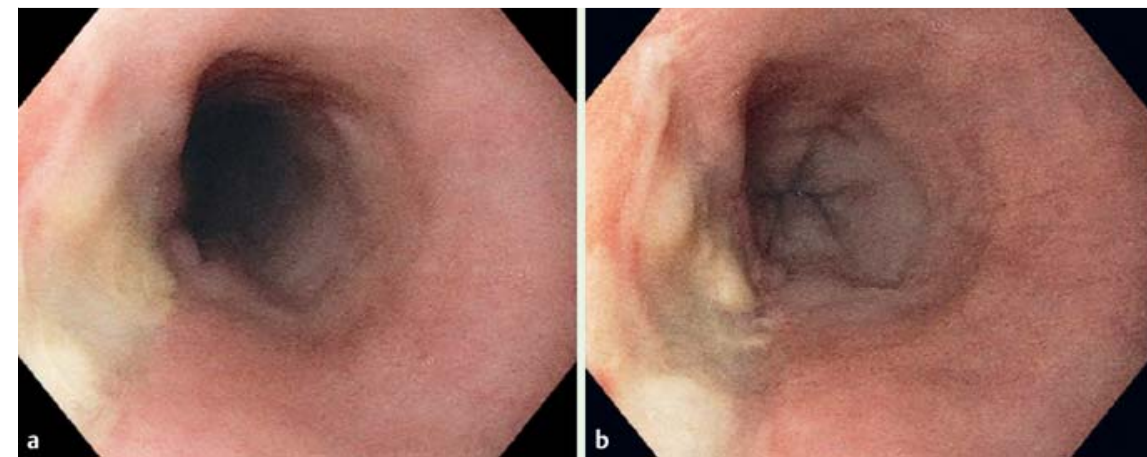

Fig. 5 Esophageal mucosa 14 days after perforation. a There are no signs of persisting perforation. b The mucosal defect is closed.

Spontaneous esophageal perforation, socalled Boerhaave syndrome, occurs after vomiting. The most frequent symptoms are pain, dyspnea, emphysema, pneumomediastinum, and nausea/vomiting [1]. The mortality rate reaches $40 \%$ once symptoms of sepsis occur $[1,2]$. Endoscopic sponge therapy is a successful approach to the treatment of esophageal defects $[3,4]$ when the sponge is pushed into the wound cavity. Reported cases of patients with Boerhaave syndrome or iatrogenic esophageal perforation demonstrate that EndoVac (SybronEndo, Orange, California, USA) may even be the best choice for conservative treatment and does not result in relevant long-term side effects [3,4]. A recent study demonstrated that in cases of anastomotic esophageal leak refractory to stenting alone, the stent-over-sponge (SOS) approach may be a valuable technique [5]. In this particular case, neither overstenting nor placement of the sponge into a cavity was possible because of the anatomical location near the UES. Nonetheless, it was possible to seal the transmural defect permanently with entirely luminal placement of the sponge.

Endoscopy_UCTN_Code_TTT_1AO_2AI

Competing interests: None

\section{Michael Scharl, Nadine Stanek, Arne Kröger, Peter Bauerfeind, Christoph Gubler}

Clinic of Gastroenterology and Hepatology, University Hospital Zurich, Zurich, Switzerland

\section{References}

1 Nirula R. Esophageal perforation. Surgical Clin North Am 2014; 94: 35-41

2 Granel-Villach L, Fortea-Sanchis C, MartinezRamos $D$ et al. Boerhaave's syndrome: a review of our experience over the last 16 years [in Spanish]. Rev Gastroenterol Mex 2014; 79: $67-70$

3 Loske G, Schorsch T, Muller C. Endoscopic vacuum sponge therapy for esophageal defects. Surg Endosc 2010; 24: 2531 - 2535

4 Schorsch T, Muller C, Loske G. Endoscopic svacuum therapy of anastomotic leakage and iatrogenic perforation in the esophagus. Surg Endosc 2013; 27: 2040-2045

5 Gubler C, Schneider PM, Bauerfeind P. Complex anastomotic leaks following esophageal resections: the new stent over sponge (SOS) approach. Dis Esophagus 2013; 26 : 598-602

\section{Bibliography}

Dol http://dx.doi.org/

10.1055/s-0034-1392029

Endoscopy 2015; 47: E293-E294

(c) Georg Thieme Verlag KG

Stuttgart · New York

ISSN 0013-726X

\section{Corresponding author}

\section{Christoph Gubler, MD}

Clinic of Gastroenterology and Hepatology University Hospital Zurich

Rämistrasse 100

8091 Zurich

Switzerland

Fax: +41-44-255-9497

christoph.gubler@usz.ch 